\title{
IMPLICAÇÕES DO PROCESSO DE SELEÇÃO DE CANDIDATOS NA COMPETIÇÃO PARTIDÁRIA: OCASO BRASILEIRO
}

\author{
Maria do Socorro Sousa Braga
}

\author{
Oswaldo E. do Amaral
}

\begin{abstract}
RESUMO
Os partidos políticos, apesar de crescentes questionamentos quanto à sua capacidade de representação, continuam exercendo funções fundamentais para o bom funcionamento dos regimes democráticos. Entre essas funções está a de articulação entre os cidadãos e as esferas de poder político, que acontece, especialmente, por meio do processo de seleção de candidatos a cargos eletivos. Mas quais são os efeitos do processo de seleção de candidatos sobre a competição política para a Câmara dos Deputados no Brasil? Com o objetivo de responder a essa questão, o artigo cumpre com uma dupla tarefa: Identificar os fatores que teoricamente afetam o processo de seleção de candidatos a cargos eletivos proporcionais, e suas consequências para o sistema partidário; e verificar qual é o controle que as lideranças dos partidos analisados apresentam sobre a composição da lista partidária. Para cumprirmos os objetivos levantados, analisamos os dados relativos às eleições para a Câmara dos Deputados, no estado de São Paulo, em 2006 e 2010. Mostramos que há uma coordenação que envolve o número de candidatos, o espaço geográfico em que competem e o seu perfil socioocupacional, além da própria distribuição de recursos partidários. O trabalho aponta que os partidos brasileiros não são tão fracos e desorganizados como parte da literatura indica. Sugerimos que os partidos são capazes de agir de maneira coordenada nas eleições para a Câmara, estabelecendo estratégias de acordo com elementos mais conjunturais (a perspectiva de contar com "puxadores" de votos, por exemplo) ou estruturais (a necessidade de organizar a lista geográfica e socialmente para coordenar recursos).
\end{abstract}

PALAVRAS-CHAVE: partidos políticos; seleção de candidatos; eleições proporcionais; competição partidária.

\section{INTRODUÇÃO ${ }^{1}$}

Quais os condicionantes do processo de seleção de candidatos que afetam a competição política para a Câmara dos Deputados no Brasil? Para muitos estudiosos, os partidos políticos teriam pouca influência nesse processo. Isso ocorreria ao menos por dois motivos interligados: primeiro, porque os partidos brasileiros seriam frágeis organizacionalmente, apenas homologando as candidaturas nas convenções partidárias; segundo, os partidos não teriam controle sobre a formação da lista partidária, devido à legislação eleitoral. $\mathrm{O}$ dispositivo da candidatura nata, que perdurou até 2002, por meio do qual os parlamentares garantiam automaticamente sua vaga nas chapas partidárias, explicaria em grande medida essa fraqueza dos partidos. Além disso, a combinação de representação proporcional e lista aberta, ao maximizar a influência dos eleitores na seleção de quais candidatos seriam eleitos, reforçaria a reputação individual em

\footnotetext{
1 Gostaríamos de agradecer aos pareceristas anônimos da Revista de Sociologia e Politica por sua contribuição para este artigo.
}

detrimento da partidária, o que teria implicações tanto sobre o comportamento dos candidatos no interior das listas, instigando a competição entre eles, quanto sobre a natureza dos vínculos entre parlamentares e partidos na arena legislativa. Nesse último caso, argumenta-se que quanto maior a autonomia do candidato eleito em relação ao partido ao longo do processo eleitoral, maior seria a sua independência na atuação parlamentar (MAINWARING, 1991; 1999; AMES, 1995; 2001; SAMUELS, 2001).

Todavia, na contramão dessa interpretação, argumentamos que, no caso brasileiro, os partidos controlam o processo de seleção dos candidatos para a Câmara dos Deputados, por meio do qual escolhem aqueles quadros que estão mais de acordo com critérios estratégicos visando a composição de uma lista partidária viável eleitoralmente. Como sabemos, desde 2002, o propalado dispositivo da candidatura nata foi extinto. Além disso, como bem demonstrou Santos (1999), a grande maioria dos candidatos, devido ao alto quociente eleitoral, precisa dos votos dos demais integrantes da lista para eleger-se e não conta com informações sobre quais eleitores votaram neles. Sendo assim, o sistema eleitoral também cria incentivos para 
um comportamento coletivo por parte dos políticos, pois, ao agirem como um time, podem reduzir as incertezas da competição política. Argumentamos que quanto maior o controle dos dirigentes partidários sobre a coordenação do processo eleitoral e, mais especificamente, sobre a formação da lista partidária, que envolve as articulações de cooperação com os demais partidos, maior a influência do partido sobre o comportamento dos políticos.

Se o raciocínio desenvolvido até aqui estiver correto, as evidências deverão mostrar: (i) que os dirigentes partidários controlam o processo de seleção dos candidatos a cargos eletivos, resultando na formação de listas partidárias estrategicamente viáveis eleitoralmente. Para isso, supomos que os partidos, mesmo com incentivos da fórmula eleitoral para apresentar o número máximo de candidatos permitidos, têm agido em duas frentes: (a) construir estratégias no que toca ao número de candidatos que compõem a lista, alterando seu comportamento de uma eleição para outra de acordo com a conjuntura eleitoral; (b) manter e incentivar certa quantidade de candidatos competitivos em suas chapas, tendo em vista o alto grau de concorrência nos contextos eleitorais estaduais; (ii) que ao menos dois critérios são levados em conta pelas lideranças partidárias na organização dessa lista: (a) o "geográfico", que implica a seleção de candidatos de diferentes regiões dos estados, evitando, assim, que haja disputa entre candidatos na mesma área; (b) a "diversidade social", que redunda na incorporação de filiados influentes junto a diferentes segmentos do eleitorado, efeito direto da lista ser aberta. Esses dois fatores (as diversidades territorial e social) já foram sugeridos por Nicolau (2007, p. 102) como primordiais para os organizadores das listas partidárias, embora a hipótese não tenha sido demonstrada.

Para encaminhar essa discussão, organizamos este trabalho em três partes. Na próxima seção, discutiremos os fatores que teoricamente afetam o processo de seleção de candidatos a cargos eletivos proporcionais e suas consequências para o sistema partidário. Na terceira seção, a partir da análise de dados das eleições para a Câmara dos Deputados, no estado de São Paulo, em 2006 e 2010, checamos as hipóteses levantadas. Na última, tecemos as considerações finais.

\section{ALGUNS CONDICIONANTES DO PROCESSO DE SELEÇÃO DE CANDIDATOS A CARGOS ELETIVOS}

Com o advento dos partidos políticos no século XIX, a relação entre governante e governados deixou de ser direta. Desde então, antes de serem escolhidos pelos eleitores, os representantes passaram a ser selecionados pelos partidos. Este artigo acompanha boa parte da literatura sobre a relação entre os partidos e o processo de seleção dos quadros eletivos, a qual investiga os condicionantes dessa atividade partidária a partir da perspectiva institucionalista. Segundo essa literatura, a influência do partido no processo de seleção de candidatos varia conforme o tipo de sistema eleitoral e a estrutura de autoridade partidária (DUVERGER, 1970; MAINWARING, 1991; KATZ, 2001; RAHAT \& HAZAN, 2001). O argumento é que, em um sistema eleitoral proporcional com lista fechada, os partidos têm pleno controle sobre esse processo, pois além de escolherem os candidatos que vão disputar as cadeiras parlamentares por sua legenda, também ordenam previamente a lista de candidatos.

Já a combinação de representação proporcional com a lista aberta, ao aumentar a influência dos eleitores na seleção de quais candidatos serão eleitos, diminuiria o controle das lideranças partidárias sobre esse processo de indicação. No caso dos partidos brasileiros, seu peso seria praticamente inexistente devido ao dispositivo da candidatura nata. Com essa regra, vigente até o pleito municipal de 2000, ocupantes de cargos eletivos proporcionais nas três esferas de poder tinham automaticamente o direito de figurar na chapa partidária para o mesmo cargo político nos pleitos seguintes, independentemente da decisão do seu partido ${ }^{2}$.

No que tange à estrutura de autoridade partidária, a suposição é que, enquanto nos partidos centralizados as lideranças nacionais têm mais peso no processo de seleção dos candidatos, controlando o acesso à lista, nos partidos com estrutura descentralizada as decisões seriam tomadas na esfera local e as lideranças não deteriam o controle das indicações, o que levaria a um

\footnotetext{
2 A candidatura nata foi introduzida no ordenamento jurídico do país por meio da Lei n. 6 055, promulgada em 17 de junho de 1974. A lei estabeleceu as regras para as eleições daquele ano e previu, em seu artigo $8^{\circ}$, que deputados federais e estaduais deveriam ser considerados candidatos natos nos seus partidos. De acordo com Porto $(2000$, p. 92$)$ a candidatura nata garantia ao parlamentar detentor de mandato o direto de concorrer ao mesmo cargo no pleito subseqüente, independentemente da aprovação do partido a que estava filiado. A partir de então, a candidatura nata incorporou-se às normas que regeram a maior parte das eleições do país. Seu histórico foi o seguinte: foi repetida em 1978; ampliada aos senadores e aos vereadores no pleito de 1982; não figurou nas normas relativas a 1986, 1990 e 1992; retornou nas eleições municipais de 1988 e de 1996 e nas gerais de 1994, além de constar na Lei n. 9 504/97, que passou a regulamentar todas as disputas do país, sendo, então, adotada em 1998 e em 2000. Deixou de ser aplicada desde que, em 24 de abril de 2002, no julgamento da medida cautelar da Ação Direta de Inconstitucionalidade (ADI) n. 2 530-9, promovida pelo então Procurador-Geral da República, Geraldo Brindeiro, o Supremo Tribunal Federal (STF) suspendeu-se a eficácia do parágrafo $1^{\circ}$ do artigo $8^{\circ}$ da Lei n. 9 504/97.
} 
maior esforço individual dos postulantes para compor a lista partidária (DUVERGER, 1970; CAREY \& SHUGART, 1995). Em conseqüência, esperar-se-iam vínculos mais frouxos entre os partidos e seus deputados no parlamento, redundando em fraca coesão e disciplina na arena legislativa.

No Brasil, o diagnóstico predominante é que, excetuando os partidos de esquerda, os demais partidos apresentariam organizações nacionais muito fracas, prevalecendo o poder decisório nas instâncias estaduais. Segundo Mainwaring (2001, p. 309), a irrelevância das organizações partidárias nacionais na escolha de candidatos causaria a emergência de partidos de tipo "catch-all", com bancadas ideologicamente heterogêneas e dirigentes nacionais com pouco poder sobre os deputados, o que redundaria em baixa disciplina parlamentar.

Carey e Shugart (1995) verificaram que a combinação de representação proporcional e lista aberta maximiza a influência dos eleitores na seleção de quais candidatos serão eleitos. Para eles, esse tipo de sistema contribuiria para diminuir o poder dos grupos dirigentes partidários. Os autores também ressaltam que a lista aberta "sem controle da indicação" seria encontrada apenas no Brasil e na Finlândia. Mas, enquanto na Finlândia os candidatos coletam assinaturas dos eleitores e apresentam ao partido uma lista de candidatos com os quais gostariam de aliar-se, no Brasil a falta de controle das lideranças partidárias devia-se ao dispositivo da candidatura nata.

No mesmo sentido, Mainwaring (1992) já tinha defendido que o controle das lideranças sobre o processo de seleção e de formação da lista de candidatos seria fraco no Brasil quando comparado aos praticados por partidos europeus. Tal dedução baseia-se na observação das regras do sistema eleitoral e na natureza descentralizada do processo de seleção dos candidatos a cargos eletivos. No que diz respeito à variável institucional, isso ocorreria em função dos dois elementos do sistema eleitoral, já citados acima: a adoção tanto da "lista partidária aberta" quanto da "candidatura nata", que estimulariam o individualismo nas campanhas eleitorais em detrimento de estratégias partidárias coletivas.

Nesse sentido, o Brasil apresentaria a combinação mais desfavorável à criação de partidos políticos nacionais fortes: representação proporcional com lista aberta e estrutura organizacional descentralizada. A principal conseqüência disso seria a conformação de partidos inconsistentes programaticamente e com débil controle sobre as principais decisões partidárias no que se refere à dinâmica de representação.

No entanto, estudos mais recentes, como os de
Guarnieri (2004; 2011), Braga (2009; 2010), Braga e Bolognesi (2012), demonstram que, no contexto brasileiro, mesmo com as características institucionais já apontadas, os líderes partidários têm importantes poderes formais e informações sobre o acesso dos filiados à lista de candidatos, contando, portanto, com um importante grau de controle indireto sobre a futura composição e ordenamento da lista apresentada aos eleitores. Aqui, conforme a legislação eleitoral e partidária, os partidos, além de terem o monopólio da representação política, não sendo permitida a candidatura independente, ainda têm autonomia para realizarem o recrutamento político, tanto dos membros que vão administrar a estrutura partidária quanto dos filiados que vão disputar um cargo eletivo. Isso ocorre porque a legislação partidária estabelece que as normas e os critérios para a seleção dos candidatos devem ser definidos pelo regimento interno de cada partido ${ }^{3}$. E são justamente os critérios privilegiados pelas lideranças partidárias para selecionar aqueles filiados que farão parte das chapas que foram pouco analisados pelos estudiosos preocupados com essa dimensão do processo político-partidário ${ }^{4}$. Ao identificarmos esses critérios e as estratégias partidárias para a formação de listas competitivas, estaremos demonstrando, por sua vez, que os dirigentes partidários vêm controlando um processo vital para a sobrevivência do partido político como ator fundamental para o funcionamento da democracia representativa.

\section{TESTANDO AS HIPÓTESES}

Para testamos as hipóteses levantadas, a análise empírica proposta contempla a avaliação de algumas práticas adotadas por todos os partidos que elegeram ao menos um representante nas eleições de 2006 e de 2010 para a Câmara dos Deputados no estado de São

\footnotetext{
3 De acordo com a legislação, as agremiações somente têm de atender a uma única exigência, que é a realização de uma convenção no âmbito estadual para a formalização da chapa de candidatos. Também estipulam os períodos para que isso aconteça. Enquanto as convenções devem ocorrer entre os dias 10 e 30 de junho do ano eleitoral, a lista de candidatos deve ser registrada até o dia 5 de julho na Justiça Eleitoral (Lei n. 9 504/97).

4 Braga (2010) iniciou a investigação dos critérios elaborados pelas lideranças partidárias comparando as listas partidárias formadas pelos principais partidos para as eleições para a Câmara dos Deputados de 2002 e 2006 nos estados de São Paulo e Rio Grande do Norte. Segundo a autora, "a liderança partidária está controlando o número de candidatos competitivos nas listas de postulantes de dois modos. Primeiro, eles apresentam um número de candidatos viáveis mais baixo do que a magnitude do distrito. Isso foi demonstrado nos dois estados examinados. Segundo, seus dirigentes evitam candidatos que concorrem na mesma região, reduzindo a competição entre os candidatos do mesmo partido" (idem, p. 2; tradução dos autores).
} 
Paulo 5

Nosso objetivo nesta seção é, a partir dos dados coletados, avaliar algumas estratégias adotadas pelos partidos na montagem de suas listas eleitorais, visando identificar alguns dos critérios usados por suas lideranças para manter o controle da entrada nas esferas de poder.

Para testarmos a hipótese de que os dirigentes partidários controlam o processo de seleção dos candidatos a cargos eletivos, resultando na formação de listas partidárias estrategicamente viáveis eleitoralmente, verificamos qual foi o número de candidatos apresentados pelos partidos analisados. A primeira constatação que podemos fazer a partir dos números apresentados na Tabela 1 é que os partidos não lançam todos os candidatos que a legislação permite. Esse é um achado contraintuitivo quando levamos em conta o sistema eleitoral brasileiro. Conforme apontado em diversos trabalhos (MAINWARING, 1991; 1999; AMES, 1995; 2001; SAMUELS, 2001), nosso sistema enfraqueceria o controle dos partidos sobre o comportamento dos candidatos e incentivaria a individualização da competição eleitoral. Dessa forma, seria de imaginarse que todos os partidos chegassem ao menos perto de lançar o número máximo de candidatos permitido.
No entanto, quando observamos as eleições para a Câmara dos Deputados, em São Paulo, em 2006 e em 2010, notamos que, no primeiro pleito, nenhuma agremiação chegou nem mesmo a apresentar $70 \%$ do total possível $\left(105\right.$ candidatos $\left.^{6}\right)$. Já em 2010, apenas o PV e o PTB chegaram próximos ao número máximo, inscrevendo em suas listas 87 candidatos ( $83 \%$ do total).

A constatação de que os partidos não preenchem, na sua maioria, o número de vagas disponíveis para os candidatos serve como um primeiro indício de que existe, por trás da elaboração das listas, alguma estratégia partidária. Essa evidência ganha força quando observamos que algumas agremiações apresentam uma variação muito grande no número de candidatos entre os pleitos. O PP, por exemplo, apresentou 33 candidatos em 2006 e $61 \mathrm{em} 2010$. O PSOL caminhou em sentido semelhante, pulando de 23, em 2006, para 66 candidatos em 2010. No sentido inverso, o PL-PR passou de 57 candidatos para apenas sete entre os dois pleitos. Já o PPS cortou pela metade o número de candidatos, reduzindo o número de 48 para 24. Não nos parece que essa variação esteja sujeita apenas ao desejo de membros do partido em candidatarem-se ou não. O que ela sugere é uma ação coordenada por parte da agremiação para tentar maximizar seus ganhos eleitorais (Tabela 1).

TABELA 1 - TOTAL DE CANDIDATOS E ELEITOS PARAA CÂMARA DOS DEPUTADOS, POR PARTIDO, EM SÃO PAULO, NOS PLEITOS DE 2006 E 2010

\begin{tabular}{|l|c|c|c|c|}
\hline \multirow{2}{*}{} & \multicolumn{2}{|c|}{2006} & \multicolumn{2}{c|}{ 2010 } \\
\cline { 2 - 5 } & Candidatos & Eleitos & Candidatos & Eleitos \\
\hline PC do B & 2 & 1 & 11 & 2 \\
PDT & 55 & 3 & 45 & 3 \\
PFL-DEM & 36 & 5 & 25 & 6 \\
PL-PR & 57 & 2 & 7 & 4 \\
PMDB & 49 & 3 & 60 & 1 \\
PP & 33 & 5 & 61 & 4 \\
PPS & 48 & 2 & 24 & 3 \\
PSB & 66 & 4 & 68 & 7 \\
PSC & 61 & 1 & 58 & 2 \\
PSDB & 67 & 18 & 48 & 13 \\
PSOL & 23 & 1 & 66 & 15 \\
PT & 58 & 14 & 57 & 2 \\
PTB & 51 & 4 & 87 & 5 \\
PV & 69 & 5 & 87 & 2 \\
Outros & 279 & 2 & 325 & 70 \\
Total & 954 & 70 & 1029 & \\
\hline
\end{tabular}

FONTE: Elaboração dos autores a partir do Tribunal Superior Eleitoral (TSE, 2012).

${ }^{5}$ Partido da Frente Liberal-Democratas (PFL-DEM), Partido
Comunista do Brasil (PC do B), Partido Democrático Trabalhis-
ta (PDT), Partido do Movimento Democrático Brasileiro
(PMDB), Partido Progressista (PP), Partido Popular Socialista (PPS), Partido Liberal-Partido da República (PL-PR), Partido Socialista Brasileiro (PSB), Partido Social Cristão (PSC), Parti- 
Uma análise mais detalhada dos dados indica a existência de um cálculo estratégico que envolve a perspectiva de contar com candidatos de grande apelo junto ao eleitorado e a possibilidade de amplificar o desempenho deles. Esse parece ser um dos cálculos que muitos partidos realizam no momento de montagem das listas partidárias. Contar com "puxadores" de voto é um ativo importante nas eleições para a Câmara dos Deputados. Dadas as características do sistema eleitoral brasileiro, os votos acumulados por esses candidatos auxiliam na eleição de outros candidatos do mesmo partido ou coligação. Nessa análise, separamos os "puxadores" de votos em duas categorias: $(i)$ candidatos "bons de voto"7 e (ii) "supercandidatos"8. A primeira é composta por aqueles que obtiveram votação entre $50 \%$ e $90 \%$ do quociente eleitoral do distrito. A segunda, por candidatos que obtiveram mais de $90 \%$ do quociente eleitoral.

Como esperado, encontramos uma associação, medida pela correlação de Spearman, significativa e alta entre o número de "puxadores" de votos (bons e supercandidatos) e o número de candidatos eleitos, por partido, tanto nas eleições de 2006 ( $r=.689$; sig. $<0,01 ; \mathrm{N}=14)$ quanto nas de $2010(r=.728$; sig. $<$ 0,$01 ; \mathrm{N}=14$ ). Já os testes envolvendo o número de candidatos e a quantidade de eleitos não se mostraram estatisticamente significativos tanto para as eleições de 2006 quanto para as de 2010 (sig. < 0,05). Além disso, todos os partidos que contaram com pelo menos um supercandidato elegeram ao menos três deputados federais nos dois pleitos.

Dadas as vantagens de contar com "puxadores" de votos, é natural que essa possibilidade faça parte dos cálculos dos partidos políticos durante o processo de seleção de candidatos. Reduzir o número de postulantes para concentrar recursos organizativos,

do da Social Democracia Brasileira (PSDB), Partido Socialismo e Liberdade (PSOL), Partido dos Trabalhadores (PT), Partido Trabalhista Brasileiro (PTB) e Partido Verde (PV). O Partido da Frente Liberal (PFL) passou a chamar-se Democratas (DEM) em 2007. O Partido da República (PR) sucedeu o Partido Liberal (PL) em 2006.

${ }^{6}$ A legislação eleitoral estabelece que os partidos, se competirem sozinhos nas eleições proporcionais, podem confeccionar listas com até uma vez e meia o número de vagas em disputa. Se competirem em aliança, a coligação pode apresentar até duas vezes mais candidatos do que o número de vagas em disputa (Lei n. 9 504/97). O estado de São Paulo possui 70 vagas na Câmara dos Deputados.

7 "Bom de voto" é aquele que representa entre 50\% e 90\% do quociente eleitoral.

8 "Supercandidato" é aquele que representa mais de $90 \%$ do quociente eleitoral. como a mobilização de militantes, diretórios e comissões provisórias municipais, além de permitir uma alocação maior do tempo de rádio e televisão para os candidatos com maior potencial eleitoral, é uma estratégia que pode render bons frutos. Inversamente, a perspectiva de não contar com "puxadores" de votos pode induzir as lideranças partidárias a investirem na ampliação do número de candidatos com o objetivo de obterem maior penetração eleitoral no distrito. Nos casos que analisamos, encontramos algumas evidências, ainda que preliminares, de que a alteração das estratégias eleitorais com relação ao número de postulantes pode ter, na perspectiva de contar ou não com candidatos de grande apelo junto ao eleitorado, um de seus elementos definidores.

Entre os sete partidos que claramente alteraram suas estratégias, ou seja, que apresentaram uma variação substantiva no número de integrantes na lista entre as eleições para a Câmara em 2006 e 2010 (30\% ou mais), a Tabela 2 mostra que quatro apresentaram mudanças como as descritas. Como mencionamos, o PP passou de 33 nomes na lista, em 2006, para 61, em 2010. No primeiro pleito, contou com dois supercandidatos e, no seguinte, com um supercandidato e um bom de voto. O PC do B, por sua vez, ampliou de dois para 11 o número de candidatos entre as duas eleições. Em 2006, a agremiação contou com um candidato bom de voto. Em 2010, com nenhum. Já o PFL-DEM caminhou no sentido inverso: Entre 2006 e 2010, passou de 36 para 25 nomes e de dois candidatos bons de voto para um supercandidato e dois bons de voto. No mesmo rumo foi o PL-PR, embora com mudanças de maior intensidade. $\mathrm{O}$ partido passou de 57 postulantes a uma vaga na Câmara, em 2006, para apenas sete em 2010. Em 2006, a agremiação não contou com nenhum "puxador" de votos e, em 2010, teve dois candidatos bons de voto e um supercandidato.

Ainda de acordo com as informações contidas na Tabela 2, os outros três partidos que alteraram suas estratégias com relação ao número de candidatos foram o PPS, o PTB e o PSOL. O primeiro reduziu pela metade o número de nomes (de 48 para 24) entre 2006 e 2010 e não apresentou, em 2010, nenhum candidato com votação superior a $50 \%$ do quociente eleitoral (em 2006, teve um candidato acima dessa marca). No entanto, o PPS conseguiu ampliar o número de eleitos de dois para três. É provável que a alteração da estratégia do PPS tenha levado em consideração o fato de integrar, em 2010, uma coligação com o PSDB e o DEM. Imaginando que esses partidos apresentariam candidatos com o potencial de alavancar o número de vagas destinadas à coligação, é possível que a liderança partidária tenha optado por reduzir o número de nomes e concentrar recursos para que, ao final do pleito, 
alguns deles conseguissem uma boa posição dentro da coligação. Já o PTB apresentou um aumento significativo no tamanho de sua lista (de 51 para 87 ) e manteve um candidato bom de voto em ambos os pleitos. O único partido que destoou claramente foi o
PSOL, que quase triplicou o número de candidatos (de 23 para 66) e, em 2010, apresentou também um candidato "bom de voto", o que não acontecera em 2006.

TABELA 2 - NÚMERO DE CANDIDATOS, DE CANDIDATOS "BONS DE VOTO" E DE "SUPERCANDIDATOS" NOS PARTIDOS QUE ALTERARAM SUA ESTRATÉGIA COM RELAÇÃO AO TAMANHO DA LISTA ENTRE 2006 E 2010 NAS ELEIÇÕES PARAACÂMARA, EM SÃO PAULO

\begin{tabular}{|l|c|c|c|c|c|c|}
\hline & \multicolumn{5}{|c|}{2006} & \multicolumn{3}{c|}{2010} \\
\cline { 2 - 7 } & Candidatos & Bons de voto & Supercandidatos & Candidatos & Bons de voto & Supercandidatos \\
\hline PC do B & 2 & 1 & 0 & 11 & 0 & 0 \\
PFL-DEM & 36 & 2 & 0 & 25 & 2 & 1 \\
PL-PR & 57 & 0 & 0 & 7 & 2 & 1 \\
PP & 33 & 0 & 2 & 61 & 1 & 1 \\
PPS & 48 & 1 & 0 & 24 & 0 & 0 \\
PSOL & 23 & 0 & 0 & 66 & 1 & 0 \\
PTB & 51 & 1 & 0 & 87 & 1 & 0 \\
\hline
\end{tabular}

FONTE: Elaboração dos autores a partir do Tribunal Superior Eleitoral (TSE, 2012).

Nota: candidato "Bom de voto" é aquele postulante que obteve votação entre $50 \%$ e $90 \%$ do quociente eleitoral; e o Supercandidato é aquele candidato que logrou votação acima de $90 \%$ do quociente eleitoral.

A segunda hipótese a ser checada diz respeito aos dois critérios que, segundo Nicolau (2007), devem ser levados em conta pelas lideranças partidárias na organização da lista: (i) o geográfico e (ii) a diversidade social. Para avaliarmos se a distribuição geográfica é um elemento importante na estratégia de composição das listas, analisamos os resultados das eleições para a Câmara dos Deputados, em São Paulo, por município, tanto em 2006 quanto em 2010. Nosso objetivo foi identificar a sobreposição de candidatos competitivos nas mesmas localidades. Para isso, separamos os candidatos que obtiveram ao menos $5 \%$ dos votos válidos em cada um dos 645 municípios e observamos se pertenciam ou não ao mesmo partido. Os resultados encontrados corroboram a hipótese levantada. Nos dois pleitos, foi bastante elevada a porcentagem de municípios em que os partidos apresentaram apenas um candidato competitivo (com mais de $5 \%$ dos votos válidos). Tomando por base o total de municípios em que cada partido contou com candidatos competitivos, identificamos que, nos dois pleitos, nenhuma agremiação apresentou um nível de sobreposição de candidatos superior a $27 \%$. É necessário destacar também que, entre os 28 casos observados, apenas seis sobrepuseram candidatos competitivos em mais de $10 \%$ das localidades (Tabela 3 ). 
TABELA 3 - NÚMERO DE CIDADES COM CANDIDATOS COMPETITIVOS E PORCENTAGEM DE CIDADES COM APENAS UM CANDIDATO COMPETITIVO SOBRE O TOTAL, POR PARTIDO, NAS ELEIÇÕES PARAA CÂMARA, EM SÃO PAULO, EM 2006 E 2010

\begin{tabular}{|l|c|c|c|c|}
\hline \multirow{2}{*}{} & \multicolumn{2}{|c|}{$\mathbf{2 0 0 6}$} & \multicolumn{2}{c|}{$\mathbf{2 0 1 0}$} \\
\cline { 2 - 5 } & $\begin{array}{c}\text { Total de cidades } \\
\text { com candidatos } \\
\text { competitivos }\end{array}$ & $\begin{array}{c}\text { \% de cidades } \\
\text { com um candidato } \\
\text { competitivo }\end{array}$ & $\begin{array}{c}\text { Total de cidades } \\
\text { com candidatos } \\
\text { competitivos }\end{array}$ & $\begin{array}{c}\text { \% de cidades } \\
\text { com um candidato } \\
\text { competitivo }\end{array}$ \\
\hline PC do B & 12 & 100 & 9 & 100 \\
PDT & 87 & 93,1 & 57 & 94,7 \\
PFL-DEM & 212 & 94,8 & 299 & 87,0 \\
PL-PR & 131 & 94,7 & 282 & 89,7 \\
PMDB & 117 & 94,0 & 117 & 99,1 \\
PP & 110 & 94,5 & 153 & 96,1 \\
PPS & 115 & 90,4 & 115 & 93,0 \\
PSB & 163 & 96,9 & 168 & 92,3 \\
PSC & 79 & 94,9 & 52 & 100 \\
PSDB & 471 & 73,5 & 428 & 73,4 \\
PSOL & 3 & 100 & 3 & 100 \\
PT & 218 & 88,1 & 264 & 86,4 \\
PTB & 132 & 82 & 100 \\
PV & 125 & 92,4 & 190 & 90,5 \\
\hline
\end{tabular}

FONTE: Elaboração dos autores a partir do Tribunal Superior Eleitoral (TSE, 2012).

NOTA: "Candidato competitivo" é aquele que obteve mais de $5 \%$ dos votos válidos em uma determinada cidade.

Além do elemento de natureza geográfica, como já apontado, Nicolau (idem) indica outro fator importante para a construção das listas partidárias, vinculado à diversidade social. Para o autor, as lideranças partidárias tenderiam a privilegiar, na seleção de candidatos, "nomes com prestígio junto a setores específicos do eleitorado: líderes sindicais, de corporações profissionais e empresariais; ativistas de movimentos sociais (mulheres, negros, moradores, ambientalistas); líderes religiosos; ou personalidades que tenham se destacado em algum ramo de atividade específico (radialistas, artistas, esportistas, intelectuais)" (idem, p. 102).

Embora não tenhamos a pretensão de apresentar um teste definitivo sobre essa proposição, é possível avançar um pouco do ponto de vista empírico a partir de alguns dados que nos permitam uma avaliação preliminar sobre o grau de importância que os partidos conferem a esse elemento na montagem de suas listas. Fazemos isso por meio da análise do perfil profissional dos candidatos à Câmara, no estado de São Paulo, em 2010, segundo informações obtidas junto ao registro de candidaturas do Tribunal Superior Eleitoral (TSE).
Nossa hipótese específica é que, se as agremiações conferem alguma importância à diversidade social em suas listas, as lideranças partidárias buscariam evitar a sobreposição de candidatos competitivos com perfis semelhantes nas mesmas localidades.

Os dados obtidos junto aos 14 partidos analisados indicam que a hipótese parece correta (Tabela 4). Juntando todas as legendas, houve sobreposição de candidatos competitivos em 267 casos, no pleito de 2010. Após observarmos o perfil dos candidatos competitivos nessas localidades, encontramos a existência de 56 casos nos quais havia mais de um candidato competitivo com a mesma ocupação. Nove partidos não apresentaram nenhuma sobreposição e nenhuma agremiação contou com candidatos competitivos com perfis semelhantes em mais de $10 \%$ das cidades em que houve nomes que obtiveram mais de $5 \%$ dos votos válidos. O caso do PSDB é bastante ilustrativo nesse sentido. A análise geográfica mostrou que o partido apresentou postulantes competitivos em 428 municípios do estado. Entre esses, 26,6\% (114) tiveram mais de um candidato. Após a análise do perfil ocupacional, a porcentagem caiu para 8,7\% (41). 
TABELA4 - NÚMERO E PORCENTAGEM DE CIDADES COM MAIS DE UM CANDIDATO COMPETITIVO E DE CIDADES COM MAIS DE UM CANDIDATO COMPETITIVO COM O MESMO PERFIL OCUPACIONAL, POR PARTIDO, NAS ELEIÇÕES PARAA CÂMARA, EM SÃO PAULO, EM 2010

\begin{tabular}{|l|c|c|c|c|}
\hline & $\begin{array}{c}\text { Total de cidades } \\
\text { com mais de um } \\
\text { candidato competitivo }\end{array}$ & $\begin{array}{c}\text { \% de cidades } \\
\text { com mais de um } \\
\text { candidato competitivo }\end{array}$ & $\begin{array}{c}\text { Total de cidades } \\
\text { com mais de um } \\
\text { candidato competitivo } \\
\text { e com o mesmo } \\
\text { perfil }\end{array}$ & $\begin{array}{c}\text { \% de cidades } \\
\text { com mais de um } \\
\text { candidato competitivo } \\
\text { e com mesmo } \\
\text { perfil }\end{array}$ \\
\hline PC DO B & 0 & 0 & 0 & 0 \\
PDT & 3 & 5,3 & 0 & 0 \\
PFL-DEM & 39 & 13,0 & 4 & 1,9 \\
PL-PR & 29 & 10,3 & 0 & 0 \\
PMDB & 1 & 0,9 & 0 & 0 \\
PP & 6 & 3,9 & 1 & 0,9 \\
PPS & 8 & 7,0 & 7 & 0,1 \\
PSB & 13 & 7,7 & 0 & 0 \\
PSC & 0 & 0 & 0 & 8,7 \\
PSDB & 114 & 26,6 & 41 & 0 \\
PSOL & 0 & 0 & 0 & 1,4 \\
PT & 36 & 13,6 & 3 & 0 \\
PTB & 0 & 0 & 0 & 0 \\
PV & 18 & 9,5 & 0 & 0 \\
\hline
\end{tabular}

FONTE: Elaboração dos autores a partir do Tribunal Superior Eleitoral (TSE, 2012).

NOTA: "Candidato competitivo" é aquele que obteve mais de $5 \%$ dos votos válidos em uma determinada cidade.

Os dados apresentados nesta seção demonstram a existência de estratégias partidárias que buscam maximizar os ganhos eleitorais e o controle das lideranças sobre a formação da lista de candidatos. Mostramos como lançar uma lista com muitos ou poucos candidatos faz parte de um complexo cálculo estratégico no qual a perspectiva de contar com "puxadores" de voto é um elemento importante. Verificamos também que os partidos, independentemente do seu tamanho, da sua capacidade organizativa e do número de candidatos apresentados, buscam coordenar a composição da lista com o objetivo de minorar a competição no seu interior. A possibilidade de maior racionalização de recursos organizativos partidários, como militantes e infraestrutura em nível local, do horário gratuito no rádio e na televisão e dos recursos financeiros arrecadados, bem como a menor disputa no interior das legendas, parecem ser os motivos que induzem à adoção dessa estratégia, especialmente no seu aspecto geográfico. Por fim, sugerimos a existência de uma ação por parte da liderança partidária no sentido de garantir uma diversidade social na composição das listas, o que implicaria, como indicado por Nicolau (idem), uma dupla coordenação na composição das listas: espacial e sócio-ocupacional. Essas constatações têm repercussões importantes para o sistema político como um todo e trataremos delas nas conclusões deste artigo.

\section{CONCLUSÕES}

Apesar de crescentes questionamentos quanto à sua capacidade de representação, os partidos políticos continuam exercendo funções fundamentais para $o$ bom funcionamento dos regimes democráticos. Entre essas funções está, como acabamos de verificar na seção anterior, a articulação entre os cidadãos e as esferas de poder político, que acontece, especialmente, por meio do processo de seleção de candidatos a cargos eletivos. Mas quais são os efeitos do processo de seleção de candidatos sobre a competição política para a Câmara dos Deputados no Brasil? Para responder a essa questão, este artigo deu conta de dois objetivos. No primeiro, buscamos identificar os fatores que teoricamente afetam o processo de seleção de candidatos a cargos eletivos proporcionais, e suas consequências para o sistema partidário. Já no segundo, verificamos qual é o controle que as lideranças dos partidos analisados apresentam sobre a composição da lista partidária. Mostramos que há uma coordenação que envolve o número de candidatos, o espaço geográfico em que competem e o seu perfil sócioocupacional, além da própria distribuição de recursos partidários. Para isso, analisamos os dados relativos às eleições para a Câmara dos Deputados, no estado de São Paulo, em 2006 e 2010.

No que diz respeito ao primeiro objetivo, destacamos que, de acordo com estudiosos dessa 
temática, a influência do partido no processo de seleção de candidatos varia conforme o tipo de sistema eleitoral e a estrutura de autoridade partidária (DUVERGER, 1970; MAINWARING, 1991; KATZ, 2001; RAHAT \& HAZAN, 2001). Há certo consenso nessa literatura em torno do argumento de que em um sistema eleitoral proporcional com lista fechada os partidos têm pleno controle sobre esse processo, pois além de escolherem os candidatos que vão disputar as cadeiras parlamentares por sua legenda os partidos também ordenam previamente a lista de candidatos. Também há razoável consenso em torno da suposição de que a combinação de representação proporcional com a lista aberta, ao aumentar a influência dos eleitores na seleção de quais candidatos serão eleitos, diminuiria o controle das lideranças partidárias sobre esse processo de indicação e, ao mesmo tempo, incentivaria a competição intralista. Como vimos, para muitos analistas, no caso brasileiro, devido também à existência do dispositivo da candidatura nata até o pleito municipal de 2000, a importância dos dirigentes seria praticamente inexistente.

Já no que tange à estrutura da autoridade partidária, a suposição compartilhada por boa parte dessa literatura é que, enquanto, nos partidos centralizados as lideranças nacionais têm mais peso no processo de seleção dos candidatos, controlando o acesso à lista, nos partidos com estrutura descentralizada as decisões seriam tomadas na esfera local e as lideranças não deteriam o controle das indicações, o que implicaria maior esforço individual dos postulantes para compor a lista partidária (DUVERGER, 1970; CAREY \& SHUGART, 1995).

Nesse sentido, o sistema político brasileiro apresentaria uma combinação bastante desfavorável à configuração de partidos políticos nacionais fortes: representação proporcional com lista aberta e estrutura organizacional descentralizada. Como conseqüência, teríamos partidos fracos no plano organizativo e partidos inconsistentes tanto no aspecto programático como na sua capacidade de controle sobre a dinâmica de representação.

No entanto, apesar do contexto institucional prevalecente, as evidências empíricas discutidas neste artigo revelam que os partidos brasileiros vêm controlando o acesso e a conformação da lista de candidatos a Deputado Federal. A ação estratégica das lideranças partidárias nesse sentido foi identificada por meio da análise da quantidade e tipos competitivos de candidatos apresentados. Os partidos examinados, além de terem um número sempre menor do que aquele permitido por lei, levam em consideração a possibilidade de contarem ou não com "puxadores" de votos, buscando sempre garantir sua sobrevivência no mercado eleitoral tendo em vista a cláusula de exclusão estadual permanente, o quociente eleitoral.

Vimos ainda que outros critérios foram introduzidos pelas lideranças partidárias, visando controlar e coordenar o processo de seleção e formação das chapas. A verificação da suposição de Nicolau (2007) demonstrou que vem ocorrendo uma dupla coordenação dessas lideranças na tentativa de apresentar candidatos viáveis eleitoralmente. Como discutimos, os partidos seguem uma lógica geográfica para evitar a superposição de candidatos, reduzindo assim a competição no interior das listas. Esse fator, por sua vez, fornece incentivos para a ação coletiva do partido, o que é fundamental para o incremento e a vitalidade da organização partidária na competição eleitoral. Ao agir como um time, a agremiação aumenta seu poder de articulação e, possivelmente, de recepção de recursos de variados grupos de interesse, ampliando as margens de manobra das lideranças partidárias.

Já o critério da diversidade social dos candidatos, além de reduzir ainda mais a competição intralista, contribui para os partidos obterem apoio eleitoral junto a setores específicos da sociedade. Esse é um aspecto comum a quase todos os partidos examinados. Observando-se a composição social das listas partidárias, verificamos que os partidos brasileiros têm funcionado como canais para a integração de indivíduos de diversos grupos na ordem política existente. Os partidos de esquerda introduziram na arena política representantes dos setores populares (RODRIGUES, 2002). Porém, com o avanço da competitividade do sistema partidário ao longo do mais recente período democrático, outros participantes do processo político foram incentivados a aceitá-las. Esse foi o caso dos partidos de direita, que também lograram determinar preferências por essas ações estratégicas.

Por fim, nosso trabalho aponta, de maneira mais ampla, que os partidos brasileiros não são tão fracos e desorganizados como boa parte da literatura indica. Seguindo os passos de autores como Figueiredo e Limongi (1999; 2007), embora sob prisma distinto, sugerimos que os partidos são capazes de agir de maneira coordenada nas eleições para a Câmara, estabelecendo estratégias de acordo com elementos mais conjunturais (a perspectiva de contar com "puxadores" de votos, por exemplo) ou estruturais (a necessidade de organizar a lista geografica e socialmente, para coordenar recursos). A partir dessa verificação cabe checar, em futuras pesquisas, se outras variáveis influenciam esse processo e como esse controle está relacionado à atuação dos partidos políticos em outras arenas, como a legislativa. 
Maria do Socorro Sousa Braga (msbraga2009@gmail.com) é Doutora em Ciência Política pela Universidade de São Paulo (USP) e Professora de Ciência Política na Universidade Federal de São Carlos (UFSCar).

Oswaldo E. do Amaral (oswaldo_amaral@yahoo.com.br)é Doutor em Ciência Política pela Universidade Estadual de Campinas (Unicamp) e Professor de Ciência Política na mesma Universidade.

\section{REFERÊNCIAS BIBLIOGRÁFICAS}

AMES, B. 1995. Electoral Strategy Under Open-List Proportional Representation. American Journal of Political Science, Bloomington, v. 39, n. 2, p. 406433, May.

. 2001. Institutions and Politics in Brazil. Ann Arbor: University of Michigan.

BRAGA, M. S. S. 2009. Reclutamiento partidista y representación: procesos de selección de candidatos en la Cámara de Diputados Brasileña. In: FREIDENBERG, F. \& ALCANTÁNTARA, M. (eds.). Selección de candidatos, política partidista y rendimiento democrático. Ciudad del México: Tribunal Electoral del Distrito Federal.

2010. Consequences of Candidate Selection under Open-list Electoral System: the case of Brazil. Brazilian Studies Programme, Oxford, Occasional Paper Number BSP 5-10, p. 1-32. Disponível em: http://www.lac.ox.ac.uk/sites/sias/files/documents/ BSP-05-2010\%20-\%20BRAGA.pdf. Acesso em: 15.jan.2013.

BRAGA, M. S. S. \& BOLOGNESI, B. 2012. Dimensões do processo de seleção da classe política brasileira: autopercepções dos candidatos à Câmara dos Deputados nas eleições de 2010. In: MARENCO, A. (org.). Os eleitos. Representação e carreiras políticas em democracias. Porto Alegre: UFRGS. No prelo.

CAREY, J. M. \& SHUGART, M. S. 1995. Incentives to Cultivate a Personal Vote: a rank ordering of electoral formulas. Electoral Studies, Kidlington, v. 14, n. 4, p. 417-439. Disponível em: http://0www.olemiss.edu.umiss.lib.olemiss.edu/courses/ pol628/careyshugart95.pdf. Acesso em: 15.jan.2013.

DUVERGER, M. 1970. Os partidos políticos. São Paulo: J. Zahar.

FIGUEIREDO, A. \& LIMONGI, F. 1999. Executivo e Legislativo na nova ordem constitucional. Rio de Janeiro: Fundação Getúlio Vargas.

2007. Instituições políticas e governabilidade: desempenho do governo e apoio legislativo na democracia brasileira. In: MELO, C. R. \& ALCÁNTARA SAEZ, M. (orgs.). A democracia brasileira: balanços e perspectivas para o século XXI. Belo Horizonte: UFMG.

GUARNIERI, F. 2004. Partidos, seleção de candidatos e comportamento político. São Paulo. Dissertação (Mestrado em Ciência Política). Universidade de São Paulo.

. 2011. A força dos partidos "fracos". Dados, Rio de Janeiro, v. 54, n. 1, p. 235-258. Disponível em: http://www.scielo.br/pdf/dados/v54n1/07.pdf. Acesso em: 15.jan.2013.

KATZ, R. S. 2001. The Problem of Candidate Selection and Models of Party Democracy. Party Politics, Thousand Oaks, v. 7, n. 1, p. 277-296, Jan.

MAINWARING, S. 1991. Políticos, partidos e sistemas eleitorais: o Brasil numa perspectiva comparada. Novos Estudos, São Paulo, n. 29, p. 34-58, mar.

1992. Brazilian Party Underdevelopment in Comparative Perspective. Political Science Quarterly, New York, v. 107, n. 4, p. 677-707.

1999. Rethinking Party Systems in the Third Wave of Democratization. The case of Brazil. Stanford: Stanford University.

NICOLAU, J. 2007. O Sistema de lista aberta no Brasil. In: NICOLAU, J. \& POWER, T. (orgs.). Instituições representativas no Brasil. Balanço e reforma. Belo Horizonte: UFMG.

PORTO, E. C. 2000. Dicionário do voto. Brasília: UNB.

RAHAT, G. \& HAZAN, R. 2001. Candidate Selection Methods: an analytical framework. Party Politics, Thousand Oaks, v. 7, n. 3, p. 297-322.

RODRIGUES, L. M. 2002. Partidos, ideologia e composição social. Um estudo das bancadas partidárias na Câmara dos Deputados: São Paulo: USP.

SAMUELS, D. 2001. When Does Every Penny Count? Intra-party competition and Campaign finance in Brazil. Party Politics, Thousand Oaks, v. 7, n. 1, p. 89-110, Jan.

2008. Political Ambition, Candidate Recruitment, and Legislative Politics in Brazil. In: 
SIAVELIS, P. \& MORGENSTERN, S. (eds.). Pathways to Power: political recruitment and candidate selection in Latin America. University Park: Penn State University.
SANTOS, F. 1999. Instituições eleitorais e desempenho do presidencialismo no Brasil. Dados, Rio de Janeiro, v. 42, n. 1, p. 111-137. Disponível em: http:/ /www.scielo.br/scielo.php?pid=s001152581999000100006\&script=sci_arttext. Acesso em: 15.jan.2013.

\section{OUTRAS FONTES}

TSE. 2012. Sitio do Tribunal Superior Eleitoral. Disponível em: http://www.tse.jus.br. Acesso em: 24.jan.2013. 


\section{CANDIDATE SELECTION AND PARTY COMPETITION: THE CASE OF BRAZIL}

\section{Maria do Socorro Sousa Braga and Oswaldo Amaral}

Political parties are still essential for the good functioning of democratic regimes. One key role performed by the parties is the connection between citizens and diferent areas of political power, performed, among others, by the process of candidate selection. But what are the effects of the candidate selection process to the political competition to the Brazilian Chamber? To answer this question, this paper has two aims: Identify the aspects that affect the candidate selection process and its consequences to the party system; Analyze the control of the leadership over the candidate list. In order to do that, we analyze the data related to the elections of 2006 and 2010 to the Chamber in the state of São Paulo. We show the existence of a coordination involving the number of candidates, their profile and their electoral strongholds. The paper points that Brazilian parties are not weak and disorganized as part of the literature implies and suggests that they are capable of building electoral strategies taking into consideration both structural needs and the political scenario.

KEYWORDS: Political Parties; Candidate Selection; Elections; Party Competition. 